\title{
SISTEM PENDUKUNG KEPUTUSAN PEMILIHAN BINTANG PELAJAR MENGGUNAKAN METODE TOPSIS DI MTs YKUI SEKARGADUNG
}

\author{
Faishol Mujtahid \\ MTs YKUI Sekargadung \\ J1. Krajan Tengah, Sekargadung, Kec. Dukun, Kab. Gresik Prov. Jawa Timur 61155 \\ email : faisholmjt@gmail.com
}

\begin{abstract}
ABSTRAK
Pemilihan bintang pelajar di MTs YKUI Sekargadung adalah salah satu program tahunan yang dilakukan oleh sekolah untuk memilih siswa-siswi berprestasi pada setiap tahun pelajaran. Siswa yang masuk seleksi pemilihan bintang pelajar diambil dari tiga siswa yang memiliki nilai akademik tinggi disetiap kelas kemudian dari kandidat tersebut akan diseleksi kembali oleh panitia seleksi. Panitia seleksi hanya menggunakan kriteria berdasarkan pada nilai akademik siswa. Ini mengakibatkan hasil keputusan yang diambil itu tidak tepat dan tidak sesuai dengan yang diharapkan karena mungkin ada siswa yang memiliki nilai akademik yang sama atau ada siswa yang memiliki nilai akademik tinggi tetapi mempunyai prilaku kurang baik di sekolah. Sistem pendukung keputusan pemilihan Bintang Pelajar menggunakan metode TOPSIS yang diharapkan dapat membantu pihak sekolah dalam proses pemilihan bintang pelajar agar memperoleh hasil yang lebih akurat, efektif dan memuaskan. Pengujian Sistem menggunakan kriteria yang telah ditetapkan oleh panitia seleksi yaitu nilai akademik, nilai sikap, hafalan surat dan kompetisi yang pernah diikuti. Hasil proses perhitungan dengan metode TOPSIS dapat menghasilkan nilai dari tiap calon bintang pelajar. Calon bintang pelajar yang menempati tiga nilai tinggi dapat dijadikan rekomendasi bagi pihak sekolah dalam mengambil keputusan pemilihan bintang pelajar di MTs YKUI Sekargadung.
\end{abstract}

Kata Kunci : sistem pendukung keputusan, TOPSIS, siswa berprestasi

\section{LATAR BELAKANG}

Madrasah Tsanawiyah Yayasan Kebangkitan Ummat Islam (YKUI) Sekargadung, merupakan satu diantara banyak lembaga pendidikan madrasah yang ada di kecamatan Dukun, madrasah ini berlokasi di jalan krajan tengah desa Sekargadung Dukun-Gresik. Dalam setiap akhir tahun pelajaran Madrasah Tsanawiyah YKUI Sekargadung selalu mengadakan pemilihan bintang pelajar bagi siswa terbaiknya. Calon siswa yang masuk seleksi pemilihan bintang pelajar diambil dari tiga siswa yang memiliki nilai akdemik tinggi disetiap kelas kemudian dari siswa tersebut akan diseleksi kembali oleh panitia seleksi. Proses pemilihan harus dilakukan dengan jeli dan juga harus selektif berdasarkan kriteria penilaian yang sudah ditentukan oleh pihak panitia seleksi. sehingga dengan itu diharapkan dapat diperoleh hasil yang memuaskan dan dapat dipilih siswa terbaik yang berhak mendapat predikat bintang pelajar di Madrasah Tsanawiyah YKUI Sekargadung.

Panitia seleksi pemilihan bintang pelajar hanya menggunakan kriteria berdasarkan pada nilai akademik siswa. Ini mengakibatkan hasil keputusan yang diambil itu tidak tepat dan tidak sesuai dengan yang diharapkan sehingga dapat menimbulkan perdebatan karena keputusan siswa yang terpilih kurang maksimal karena dari beberapa calon bintang pelajar yang ada mungkin memiliki nilai akademik yang sama atau ada calon yang memiliki nilai akademik tinggi tetapi mempunyai prilaku kurang baik di sekolah.
Penyelesaian permasalahan dalam proses pemilihan bintang pelajar agar dapat memperoleh hasil yang lebih akurat dan lebih efektif dari pemilihan yang sebelumnya maka perlu merancang sebuah sistem pendukung keputusan pemilihan bintang pelajar dengan menambahkan beberapa kriteria penilaian sehingga diharapkan dapat tercapai suatu keputusan yang baik, optimal, cepat dan akurat.

Sistem ini akan dibangun dengan konsep Multiple Attribute Decision Making (MADM) sebagai pemberian kriteria, dan metode yang digunakan adalah Technique for Order Preference by Similarity to ideal Solution (TOPSIS) sebagai alternatif untuk perhitungan. Prinsip kerjanya adalah dimana alternatif yang terbaik tidak hanya memiliki jarak terpendek dari solusi akan tetapi juga memiliki jarak terpanjang dari solusi negatif. Dengan kata lain sistem akan menghasilkan hasil pemilihan bintang pelajar yang sesuai dengan harapan. Konsep ini banyak digunakan untuk menyelesaikan masalah keputusan secara praktis. Jadi, konsepnya sederhana dan mudah dipahami, komputasinya efisien dan memiliki kemampuan untuk mengukur kinerja relatif dan alternatif-alternatif keputusan dalam bentuk matematis sederhana (Kusumadewi, 2006).

\section{LANDASAN TEORI}

\subsection{Sistem Pendukung Keputusan 2.1.1 Pengertian Sistem Pendukung Keputusan}


INDEXIA: Informatic and Computational Intelegent Journal

Faishol Mujtahid

\section{Sistem Pendukung Keputusan Pemilihan Bintang Pelajar Menggunakan Metode Topsis Di Mts Ykui}

Sekargadung

Sistem Pendukung Keputusan (SPK) atau Decision Support System (DSS) adalah sebuah sistem yang mampu memberikan kemampuan pemecahan masalah maupun kemampuan pengkomunikasian untuk masalah dengan kondisi semi terstruktur dan tak terstruktur. Sistem ini digunakan untuk membantu pengambilan keputusan dalam situasi semi terstruktur dan situasi yang tidak terstruktur, dimana tak seorangpun tahu secara pasti bagaimana keputusan seharusnya dibuat (Turban, 2001).

SPK bertujuan untuk menyediakan informasi, membimbing, memberikan prediksi serta mengarahkan kepada pengguna informasi agar dapat melakukan pengambilan keputusan dengan lebih baik.

SPK merupakan implementasi teori-teori pengambilan keputusan yang telah diperkenalkan oleh ilmu-ilmu seperti operation research dan menegement science, hanya bedanya adalah bahwa jika dahulu untuk mencari penyelesaian masalah yang dihadapi harus dilakukan perhitungan iterasi secara manual (biasanya untuk mencari nilai minimum, maksimum, atau optimum), saat ini computer PC telah menawarkan kemampuannya untuk menyelesaikan persoalan yang sama dalam waktu relatif singkat.

\subsection{Metode TOPSIS (Technique for Order} Preference by Similarity to Ideal Solution)

Topsis (Technique for Order Performance by Similarity to Ideal Solution) adalah salah satu metode pengambilan keputusan multi kriteria yang pertama kali diperkenalkan oleh Yoon dan Hwang (1981). TOPSIS menggunakan prinsip bahwa alternatif yang terpilih harus mempunyai jarak terdekat dari solusi ideal positif dan juga harus memiliki jarak terpanjang dari solusi ideal negatif dari sudut pandang geometris dengan menggunakan jarak Euclidean (jarak antara dua titik) untuk menentukan kedekatan relatif dari suatu alternatif dengan solusi optimal (Kusumadewi, 2006).

Solusi ideal positif didefinisikan sebagai jumlah dari seluruh nilai terbaik yang dapat dicapai untuk setiap atribut, sedangkan solusi ideal negatif terdiri dari seluruh nilai terburuk yang dicapai untuk setiap atribut. TOPSIS mempertimbangkan keduanya, jarak terhadap solusi ideal positif dan jarak terhadap solusi ideal negatif dengan mengambil kedekatan relatif terhadap solusi ideal positif.

Topsis banyak digunakan pada beberapa model MADM untuk menyelesaikan masalah keputusan secara praktis. Hal ini disebabkan:
1. Topsis memiliki konsep yang sederhana dan mudah dipahami.

2. Komputasinya efisien.

3. Memiliki kemampuan untuk mengukur kinerja relatif dari alternatif-alternatif keputusan dalam bentuk matematis yang sederhana.

\subsubsection{Tahap-Tahap Metode Topsis}

Berikut beberapa langkah-langkah dalam menggunakan metode topsis:

1. Matriks Keputusan Ternormalisasi

Langkah pertama adalah menormalisasikan matriks keputusan, normalisasi dilakukan pada setiap atribut matriks, normalisasi dilakukan dengan cara membandingkan setiap atribut pada suatu alternatif dengan akar jumah kuadrat setiap elemen kriteria yang sama pada semua alternatif. Berikut adalah persamaan untuk melakukan normalisasi pada setiap atribut matriks kebutuhan.

$$
r_{i j} \frac{x_{i j}}{\sqrt{\sum_{i=1}^{m} x_{i j}^{2}}}
$$

Dimana $r_{i j}$ adalah nilai atribut yang telah ternormalisasi Dengan $i=1,2, \ldots, m$. Dan $j=1,2, \ldots, n$. Dan $\mathrm{x}_{\mathrm{ij}}$ adalah matriks keputusan.

2. Pembobotan nilai Matriks Keputusan ternormalisasi

Selanjutnya adalah, membuat matriks ternormalisasi terbobot dengan dilambangkan Y. Pembobotan nilai dilakukan dengan mengalikan matriks keputusan ternormalisasi dengan elemen pada vektor bobot preferensi dengan dilambangkan W. Berikut adalah persamaan untuk pembobotan:

$$
\mathrm{Y}_{\mathrm{ij}}=\mathrm{W}_{\mathrm{i}} \times \mathrm{r}_{\mathrm{ij}}
$$

Dengan $Y_{\mathrm{ij}}$ merupakan matriks ternomalisasi terbobot, $\mathrm{W}_{\mathrm{i}}$ merupakan vektor bobot, dan $\mathrm{r}_{\mathrm{ij}}$ merupakan matriks ternormalisasi. Dengan bobot $\mathrm{W}=(\mathrm{w} 1, \mathrm{w} 2, \ldots, \mathrm{Wn})$.

3. Menentukan solusi ideal Positif dan Negatif a. Solusi ideal positif

Solusi ideal positif dapat ditentukan berdasarkan rating bobot yang ternormalisasi $\left(Y_{i j}\right)$. Dengan persamaan berikut:

$$
\mathrm{A}^{+}=\left(\mathrm{Y}_{1}^{+}, \mathrm{Y}_{2}^{+}, \ldots \mathrm{Y}_{\mathrm{n}}^{+}\right) \ldots \ldots(2.3)
$$

b. Solusi ideal negatif

Solusi ideal positif juga dapat ditentukan berdasarkan rating bobot yang ternormalisasi 
INDEXIA: Informatic and Computational Intelegent Journal

Faishol Mujtahid

Sistem Pendukung Keputusan Pemilihan Bintang Pelajar Menggunakan Metode Topsis Di Mts Ykui

Sekargadung

$\left(\mathrm{Y}_{\mathrm{ij}}\right)$. Vektor solusi ideal negatif dilambangkan dengan $\mathrm{A}^{+}$Dengan persamaan berikut:

A- $=\left(\mathrm{Y}_{1}^{-}, \mathrm{Y}_{2}^{-}, \ldots \mathrm{Y}_{\mathrm{n}}^{-}\right)$

4. Menentukan jarak antara nilai setiap alternatif dengan matriks solusi ideal positif dan negatif. a. Jarak terhadap solusi ideal positif. Jarak antara alternatif $A_{i}$ dengan solusi ideal positif dirumuskan sebagai berikut:

$$
\begin{gathered}
\mathrm{D}_{\mathrm{i}}^{+}=\sqrt{\sum_{j=1}^{n}\left(Y_{i}^{+}-Y_{i j}\right)^{2}} \\
\ldots \ldots \ldots \ldots \ldots(2.5)
\end{gathered}
$$

Dimana:

$\mathrm{D}_{\mathrm{i}}^{+}=$jarak alternatif dengan solusi ideal positif

$Y_{i}^{+}=$solusi ideal positif

$Y_{i j}=$ matriks normalisasi terbobot

b. Jarak terhadap solusi ideal negatif

Jarak antara alternatif $A_{i}$ dengan solusi ideal negatif dirumuskan sebagai berikut:

$$
\begin{aligned}
& \mathrm{D}_{\mathrm{i}}^{-} \quad=\sqrt{\sum_{j=1}^{n}\left(Y_{i j}-Y_{i}^{-}\right)^{2}} \\
& \text { Dimana: } \\
& \mathrm{D}_{\mathrm{i}}^{-}=\text {jarak alternatif dengan solusi ideal positif } \\
& Y_{i j}=\text { matriks normalisasi terbobot } \\
& Y_{i}^{-}=\text {solusi ideal negatif }
\end{aligned}
$$

5. Menentukan nilai preferensi untuk setiap alternatif

Nilai preferensi merupakan nilai akhir yang menjadi patokan dalam menentukan peringkat pada semua alternatif yang ada. Berikut adalah persamaan yang menggambarkan cara untuk mendapatkan nilai preferensi untuk setiap alternatif.

$$
\mathrm{V}_{\mathrm{i}}=\frac{D_{i}^{-}}{D_{i}^{-}+D_{i}^{+}}
$$

$$
\ldots \ldots \ldots \ldots \ldots \ldots \ldots(2.7)
$$

Dengan $0<\mathrm{V}_{\mathrm{i}}<1$ dan $\mathrm{i}=1,2,3, \ldots, \mathrm{m}$

Dimana:

$\mathrm{V}_{\mathrm{i}}=$ kedekatan tiap alternatif terhadap solusi ideal positif

$D_{i}^{+}=$jarak alternatif $\mathrm{A}_{\mathrm{i}}$ dengan solusi ideal positif

$D_{i}^{-}=$jarak alternatif $A_{i}$ dengan solusi ideal negatif

6. Merangking alternatif

Alternatif dapat dirangking berdasarkan urutan $\mathrm{V}_{\mathrm{i}}$ Maka dari itu, alternatif terbaik adalah salah satu yang berjarak terpendek terhadap solusi ideal dan berjarak terjauh dengan solusi negatif-ideal. 
INDEXIA: Informatic and Computational Intelegent Journal

Faishol Mujtahid

Sistem Pendukung Keputusan Pemilihan Bintang Pelajar Menggunakan Metode Topsis Di Mts Ykui

\section{Sekargadung}

aplikasi ini mempunyai dua akun untuk hak akses yaitu kepala sekolah untuk memasukan kriteria dan nilai bobot kriteria kemudian akun admin untuk memasukan data calon bintang pelajar beserta bobot pada setiap alternatif pada masing - masing kriteria. Pada halaman ini terdapat form username dan password yang harus di isi dengan benar agar bisa masuk kedalam aplikasi. Berikut adalah tampilan halaman login yang dapat dilihat pada Gambar 4.1 Halaman Login

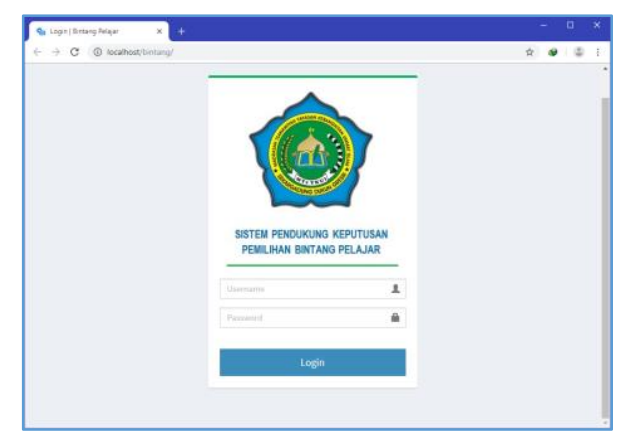

Gambar 4.1. Halaman Login

\section{Halaman Utama}

Halaman ini digunakan untuk mengakses keseluruhan menu yang ada dalam aplikasi sesuai dengan hak akses yang dimiliki oleh user. Berikut adalah tampilan halaman utama pada Gambar 4.2 halaman utama

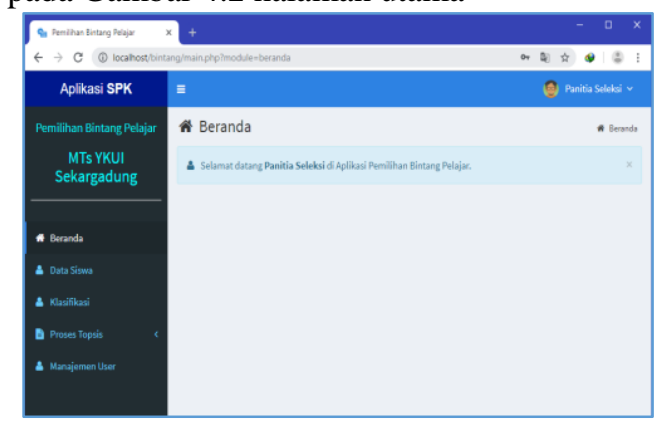

Gambar 4.2. Halaman Utama

\section{Halaman Klasifikasi}

Halaman klasifikasi digunakan untuk memasukan nilai data nilai pada setiap alternatif setiap kriteria. User admin dapat menambahkan data nilai kompetensi siswa dengan mengisi data nilai kompetensi siswa pada menu edit data klasifikasi data berikut dapat dilihat pada gambar 4.3

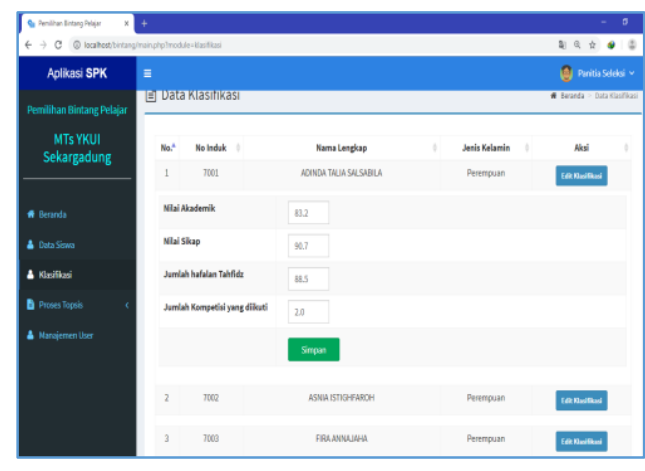

Gambar 4.3. Halaman Klasifikasi

\section{Halaman data awal perhitungan}

Pada gambar 4.4 digunakan untuk melihat data awal nilai keriteria penilaian siswa berprestasi. Didalam halaman ini ada alternatif, nama dan nilai setiap kriteria $\mathrm{C} 1, \mathrm{C} 2, \mathrm{C} 3, \mathrm{C} 4, \mathrm{C} 5$ dan $\mathrm{C} 6$ yang akan di proses. Dapat dilihat pada gambar 4.5 Halaman data awal

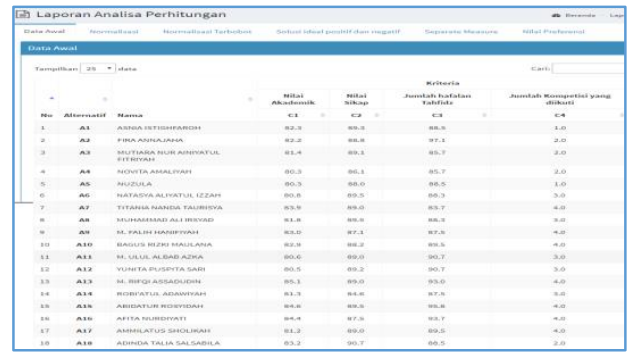

Gambar 4.4. Halaman data awal

\section{Halaman hasil perhitungan}

Halaman ini berisi hasil perhitungan dengan metode TOPSIS. Dalam halaman ini terdapat menu untuk mencetak laporan hasil proses pemilihan bintang pelajar. Berikut adalah tampilan dari halaman hasil perhitungan

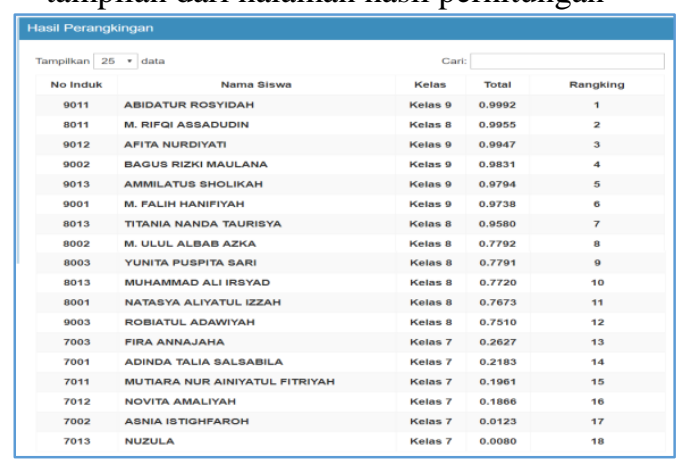

Gambar 4.5. Halaman Hasil Perhitungan

Hasil pengujian seperti yang terlihat pada gambar 4.14. Dapat disimpulkan bahwa hasil perhitungan sistem tersebut adalah hasil akhir dari proses pemilihan bintang pelajar di MTs YKUI Sekargadung dukun gresik yang akan diambil 3 
INDEXIA: Informatic and Computational Intelegent Journal

Faishol Mujtahid

Sistem Pendukung Keputusan Pemilihan Bintang Pelajar Menggunakan Metode Topsis Di Mts Ykui

Sekargadung

siswa yang menjadi bintang pelajar. Dimana di peroleh 3 siswa dengan nilai tertinggi yaitu diurutan pertama atas nama Abidatur Rosyida, kedua M. Rifqi Assaduddin dan ketiga Afita Nurdiyati.

Tabel 4.1. Hasil Pemilihan bintang pelajar berdasarkan perhitungan sistem.

\begin{tabular}{|c|l|c|}
\hline Peringkat & Nama Siswa & Nilai \\
\hline 1 & Abidatur Rosyida & 0.9992 \\
\hline 2 & M. Rifqi Asadudin & 0.9955 \\
\hline 3 & Afita Nurdiyati pemilihan bintang pelajar \\
\hline \multicolumn{2}{|c|}{ Hasil perang }
\end{tabular}

menggunakan sistem diatas selanjutnya akan dilakukan perbandingan dengan hasil pemilihan bintang pelajar tahun pelajaran 2017-2018 yang dilaksanakan disekolah saat ini. Dimana hasil pemilihan bintang pelajar yang dilaksanakan oleh pihak sekolah saat ini hanya berdasarakan pada nilai rata-rata raport atau nilai akademik. Berikut adalah Tabel 4.2 Hasil pemilihan bintang pelajar tahun 2017-2018 di sekolah.

Tabel 4.2. Hasil pemilihan bintang pelajar tahun 2017-2018 di sekolah

\begin{tabular}{|c|l|c|}
\hline Peringkat & Nama Siswa & Nilai \\
\hline 1 & M. Rifqi Asadudin & 85,10 \\
\hline 2 & Abidatur Rosyida & 84,60 \\
\hline 3 & Afita Nurdiyati & 84,46 \\
\hline
\end{tabular}

Pada table 4.1 dan 4.2 menunjukan bahwa pemilihan menggunakan perhitungan sistem dengan kondisi lapangan. Dari data diatas dapat disimpulkan bahwa nama siswa yang terpilih menjadi bintang pelajar berdasarkan perhitungan sistem dan kondisi lapangan menunjukan hasil yang sama hanya saja siswa yang terpilih menempati peringkat yang berbeda. dimana perhitungan menggunakan sistem pendukung keputusan (SPK) pemilihan bintang pelajar lebih baik dan lebih akurat. Dan dari kuesioner yang sudah dibagikan didapat kesimpulan bahwa sistem yang dibangun sudah berjalan amat baik.

\subsection{KESIMPULAN}

Setelah dilakukan perancangan, pembuatan dan uji coba sistem pendukung keputusan dengan mengguankan metode TOPSIS ini, maka ada beberapa kesimpulan yang dapat dijabarkan sebagai berikut:

1. Hasil perhitungan sistem didapatkan bahwa siswa yang terpilih menjadi bintang pelajar adalah siswa yang bernama Abidatur Rosyida dengan nilai 0.9992, kedua M. Rifqi Assaduddin dengan nilai 0.9955 dan ketiga Afita Nurdiyati dengan nilai 0.9947 .

2. Dari hasil pengujian sistem tersebut disimpulkan bahwa solusi yang diberikan oleh sistem sudah baik. Dengan demikian

metode TOPSIS merupakan metode yang sesuai untuk digunakan dalam pengambilan keputusan yang melibatkan banyak kriteria, dari hasil perhitungan sistem dan perhitungan manual sudah sesuai berarti sistem yang dibangun telah berjalan dengan benar.

3. Sistem yang dibangun ini sebagai alat bantu untuk memberikan rekomendasi kepada sekolah dalam mengambil keputusan untuk menentukan siswa yang layak menerima bintang pelajar di MTS YKUI Sekargadung

4. Dari hasil kuisoner yang sudah dibagikan ke pihak sekolah, terbukti bahwa sistem yang dibuat sudah berjalan amat baik.

\subsection{SARAN}

Saran yang dapat disampaikan untuk pengembangan sistem kedepan, adalah sebagai berikut :

1. Sebaiknya dalam sistem ditambahkan feature untuk menyimpan hasil proses perhitungan, karena saat ini sistem belum bisa manyimpan hasil perhitungan ketika dilakukan proses perhitungan dengan data yang baru.

2. Sistem dapat dikembangkan dalam bahasa pemograman lain karena sifatnya yang saat ini masih berbasis web.

\section{DAFTAR PUSTAKA}

Basyaib, Fachmi. 2006. Teori Pembuat Keputusan. Yogyakarta: Andi Offset.

Budi Utomo, Sanjaya. 2016, Sistem Pendukung Keputusan Pemberian Bonus Pegawai pada Hotel Saptanawa Gresik. Skripsi. Gresik : Universitas Muhammadiyah Gresik.

Cristian, Riko. 2014, Sistem pendukung keputusan pemberian beasiswa pada SMA Negeri 1 Panukal Utara menggunakan TOPSIS, Universitas Bina Darma.

Kusumadewi, Sri.,dkk. 2006. Fuzzy Multi-Atribute Decision Making (Fuzzy MADM). Yogyakarta. Graha Ilmu.

Rudolphi, W., 2000. "Multi Criteria Decision Analysis as A Framework for Integrated Lan Use Management in Canadian National Parks", dalam : Simon Fraser University SimoesMarques, M.; Ribeiro, R.; dan GamieroMarques, A. A Fuzzy Decision Support System for Equiment Repair Under Battle Condition. Fuzzy Sets and Systems, 115: 114157 
INDEXIA: Informatic and Computational Intelegent Journal

Faishol Mujtahid

Sistem Pendukung Keputusan Pemilihan Bintang Pelajar Menggunakan Metode Topsis Di Mts Ykui

Sekargadung

Sprague, R.H. \& Watson H.J. (1993). Decision

Support Systems: Putting Theory Into Practice. Englewood Clifts, N.J: Prentice Hall

Turban. 2001. Decision Support System and intelligent system (Sistem Pendukung Keputusan dan Sistem Cerdas). Yogyakarta, Andi

Ulum, Misbakhul. 2016, Aplikasi sistem pendukung keputusan dengan menggunakan metode topsis untuk menyeleksi penerimaan calon siswa baru (studi kasus : smk wachid hasyim glagah lamongan. Skripsi. Gresik : Universitas Muhammadiyah Gresik

Zimmermann, H.J., 1991, Fuzzy set theory and its applications, 2nd ed., Boston, Dordrecht, London: Kluwer Academic Publishers 